\title{
LA BUENA NUEVA DE LA MUJER PROFETA: IDENTIDAD Y CULTURA POLÍTICA EN LAS FOURIERISTAS Ma JOSEFA ZAPATA Y MARGARITA PÉREZ DE CELIS
}

\author{
Gloria Espigado Tocino
}

\section{Introducción}

A mediados del siglo XIX, irrumpe en la prensa española un buen número de escritoras en busca de reconocimiento literario, contribuyendo a consolidar un mercado publicístico dirigido a las mujeres ${ }^{1}$. Será una oportunidad única para expresar anhelos incumplidos y representar una imagen de la feminidad con voz propia. En unos momentos en que el discurso de la domesticidad está generando el prototipo del «ángel del hogar», que muchas de estas escritoras aceptarán de buen grado, una serie de periódicos publicados en Cádiz rompen con los esquemas de sumisión y subordinación característicos. Nos referimos a la obra editorial de dos mujeres que desarrollaron su labor publicística en la ciudad de Cádiz. Seguidoras de las doctrinas del socialista utópico francés Charles Fourier, fundaron varios periódicos que cubren una década de actividad editorial entre 1856 y 1866, dando a la luz cinco títulos por orden de aparición: El Pensil Gaditano, El Pensil de Iberia, El Nuevo Pensil de Iberia, El Pensil de Iberia y La Buena Nueva. Sus promotoras, $\mathrm{M}^{\mathrm{a}} \mathrm{Josefa}$

1. Dentro de la importante bibliografía que estudia la implicación femenina en el ámbito hemerográfico español vid., ROIG, Mercedes, La mujer y la prensa desde el siglo XVII a nuestros días, Madrid, 1977; PERINATS, Adolfo y MARRADES, Isabel, Mujer, prensa y sociedad en España. 1800-1939, Madrid, 1980; JIMÉNEZ MORELL, Inmaculada, La prensa femenina en España (desde sus orígenes a 1868), Madrid, 1992; SÁNCHEZ Llama, Iñigo, Galería de escritoras isabelinas. La prensa periódica entre 1833 y 1895, Madrid, 2000; del mismo autor, Antología de la prensa periódica isabelina escrita por mujeres (1843-1894), Cádiz, 2001. 
Zapata y Margarita Pérez de Celis, que tendrán que lidiar con la debilidad de un mercado naciente y con la censura feroz de las autoridades, no escriben la típica revista de «salón y modas» por y para mujeres con consejos domésticos y figurín incluido. Su objetivo trasciende a una literatura que no reconoce géneros y temáticas específicas según el sexo, si bien un núcleo fundamental de los temas que desarrollen partirán de la consideración de la visible marginación en que se encuentran las mujeres. Sus periódicos estuvieron abiertos a la colaboración de escritoras y de escritores de los que no resulta difícil señalar su filiación demócrata y republicana. En estas páginas, y mediante el análisis de lo que escriben en sus periódicos, buscaremos un acercamiento a la imagen que procuran de sí, la identidad que construyen con sus palabras partiendo de su realidad social, sus vivencias y sus convicciones políticas inspiradas en la doctrina del pensador de Besançon.

El fourierismo que destilan sus páginas, el vocabulario afín con el inventor del falansterio y el formulador de la ley de la atracción pasional, nos exige un breve acercamiento, una explicación, aunque sea somera, que nos resuelva la predilección de estas mujeres por el maestro nacido en Besançon. Habrá que recordar que los autores etiquetados como «socialistas utópicos»² partieron de un análisis crítico del proceso revolucionario abierto en Francia en 1789, denunciando los desequilibrios sociales que, por sí mismo, el nuevo modelo liberal no podía resolver sino más bien acrecentar. Poco atentos a los regímenes políticos, hicieron hincapié en los desórdenes económicos que el incipiente capitalismo estaba introduciendo en una sociedad en continua transformación, al mismo tiempo que analizaban críticamente la corrupción de las costumbres imperantes y los vicios de unos principios morales nefastos para la naturaleza humana. Es en este apartado particular donde algunos de ellos, fundamentalmente Robert Owen, el conde de Saint-Simon y Charles Fourier, pusieron su acento, intentando demostrar las consecuencias perniciosas del falso orden doméstico, identificado con el matrimonio monógamo y la familia, como instituciones paralizantes del progreso social, pasando a criticar el papel limitado que se otorgaba a las mujeres en este contexto de desvarío irracional. El personaje que más nos interesa, Charles Fourier (17721837), se presentó en sus obras como un verdadero paladín de la libertad de las mujeres, llegando a relacionar el avance de la civilización con el estado de libertad que las sociedades otorgasen a éstas ${ }^{3}$.

2. ENGELS, Federico, Del socialismo utópico al socialismo científico, Madrid, 1989 (1882).

3. Espigado Tocino, Gloria, «La mujer en la utopía de Charles Fourier», en RAmos, M $^{a}$ Dolores y VERA, $\mathrm{M}^{\mathrm{a}}$ Teresa (coords.), Discursos, realidades, utopías. La construcción del sujeto femenino en los siglos XIX y XX, Barcelona, 2002, pp. 321-372. 
La entrada de las ideas fourieristas en España fue propiciada por uno de los damnificados de la involución absolutista ocurrida tras el Trienio liberal. Joaquín Abreu (1782-1851), diputado en dicho periodo, marchó al exilio francés para poner a salvo su vida y durante esa estancia entabló conocimiento y contacto con los representantes de la escuela falansteriana ${ }^{4}$. De vuelta a España, difundió mediante escritos aparecidos en la prensa y en folletos divulgativos el ideario fourierista, contagiando a un puñado de escritores que multiplicaron el efecto de partida, constituyendo un núcleo gaditano de adscripción doctrinal. No sólo eso, sino que, si seguimos a Elorza en su ya clásico trabajo sobre el fourierismo en España, hubo lugar para un segundo foco madrileño a cuyo frente se situará el que será destacado dirigente republicano, Fernando Garrido ${ }^{5}$. La evolución de la escuela en España seguiría las pautas ya trazadas por los epígonos del fourierismo francés ejemplarizada en la trayectoria del discípulo Víctor Considerant, es decir, la adecuación programática del ideario fourierista hacia opciones políticas emparentadas con el demoliberalismo y la atención a los desequilibrios sociales más perentorios causados por el individualismo capitalista. Será precisamente esta segunda generación de escritores, todavía fourieristas pero orientados cada vez más hacia la acción política, en algunos casos, insurreccional, la que firmará muchos de los artículos divulgadores de las ideas asociativas y armonicistas del pensador francés en las páginas de los periódicos que analizamos: Fernando Garrido, Sixto Cámara, Francisco Pi y Margall, Roberto Robert, Roque Barcia, entre otros. Tras el eco de la revolución de 1848 en Francia y la experiencia del Bienio Progresista en España, la prensa demócrata y filorrepublicana se hará más presente en el panorama hemerográfico español y en algunos casos, como el que aquí nos ocupa, las ideas fourieristas seguirán proporcionando un sustrato ideológico propicio para sostener el tono reivindicativo.

En cuanto a las mujeres, el caso español estará lejos de reproducir la intensidad del debate francés auspiciado por la irrupción de las escuelas saintsimoniana y fourierista con sus mensajes galvanizadores y emancipadores respectivos. En Francia, la escuela saintsimoniana, encarnada en la labor divulgadora del discípulo Enfantin, desarrolló a comienzos de la década de los treinta toda una profecía mesiánica en torno a la salvación humana a partir de la llegada simbólica de la Madre. Figuras como Suzane Voilquin, Désirée Véret, Jeanne Deroin o Eugénie Niboyet, tomando como punto de partida esta escuela y alzando el vuelo por sí mismas, realizaron una encomiable labor de edición

4. CABRAL, Antonio, Socialismo utópico y revolución burguesa: El fourierismo gaditano (18341848), Cádiz, 1990.

5. ElorZA, Antonio, El fourierismo en España, Madrid, 1975. 
de prensa y apostolado que culminaría con la presentación, por supuesto vetada, de la candidatura de Jeanne Deroin a las legislativas de $1849^{6}$. Por su parte, el fourierismo también sedujo a un número significativo de mujeres en el vecino país, de las cuales podríamos aquí destacar la figura emblemática de Flora Tristán que entabló contacto durante un tiempo con el fundador de la escuela ${ }^{7}$. En contraste, la situación en España es pobre en cuanto a la representación femenina que podemos rastrear y también en la parquedad del discurso elaborado. A falta de estudios que vayan más allá de lo que en su día adelantó el trabajo pionero de Antonio Elorza, la subordinación de la mujer compone un espacio marginal y de escaso calado entre las publicaciones españolas del socialismo utópico o el republicanismo durante el reinado de Isabel II $^{8}$. Algunos artículos del introductor del fourierismo, Joaquín Abreu; alguna contestación a críticas jocosas sobre la situación de la mujer francesa, obra de Sixto Cámara, entre otros ejemplos; y la adscripción de la que Alcalá Galiano evoca como fourierista en el tramo final de su vida, la jerezana Margarita de Morla y Virués, que prologa en 1841 la obra del miembro de la escuela, Juan Czinski, El Porvenir de las Mujeres, con el título «Una palabra a las Españolas, dirigida por una compatricia», suponen la parca aportación del socialismo utópico español a la causa de las mujeres antes del medio siglo ${ }^{9}$. Es por ello que la publicación de los «Pensiles», donde la palabra «mujer» aparece con una inusitada frecuencia, y la implicación de dos escritoras como promotoras de la empresa, nos señala un hito excepcional y pionero en lo que podemos considerar los inicios de una conciencia feminista en España.

6. MOSES, Claire, «Saint-simonia Men, Saint-simonian Women: The Transformation of Feminist Thought in 1830' France», The Journal of Modern History, Vol. 54, nº 2 (1982), pp. 240-267; Riot-SARCEY, Michéle, La démocratie à l'épreuve des femmes. Trois figures critiques du pouvoir 1830-1848, Paris, 1994.

7. BAELEN, Jean, Flora Tristán: feminismo y socialismo en el siglo XIX, Madrid, 1974.

8. EloRZA, Antonio, «Feminismo y socialismo en España (1840-1868)», en Tiempo de Historia, n³ (1974); PeYrou, Florencia, El Republicanismo Popular en España 1840-1843, Cádiz, 2002, pp. 141-146 y, de la misma autora, Tribunos del pueblo. Demócratas y republicanos durante el reinado de Isabel II, Madrid, 2008, pp. 130-133.

9. SÁNCHEZ VillanueVA, Juan Luis, «Una tertuliana, una fourierista: Margarita López de Morla», en PASCUA SÁNCHEZ, Ma José de la y EsPigado Tocino, Gloria (eds.), Frasquita Larrea y Aherán. Europeas y españolas entre la Ilustración y el Romanticismo (1750-1850), Cádiz, 2003, pp. 157-180. En La Phalange, el fourierista francés François Devay comentaba la aparición del folleto el 29 de mayo de 1842, precedido del prólogo aludido firmado por Mme de V., que hace alusión al apellido Virués tomado de su esposo, Zavala, Iris, Románticos y socialistas. Prensa española en el siglo XIX, Madrid, 1972, p. 174. 


\section{Trazos biográficos y obra editorial}

Es evidente que tanto $\mathrm{M}^{\mathrm{a}}$ Josefa Zapata como Margarita Pérez de Celis no conocieron el éxito literario en su tiempo. Las escasas referencias biográficas que tenemos de ellas y el escaso reflejo en los compendios biobibliográficos de que disponemos nos hablan elocuentemente de la doble marginación que sufrieron como mujeres y como escritoras ${ }^{10}$. Probablemente, el carácter vindicativo e inconformista de los editoriales fourieristas que patrocinaron, las situó en una posición de marginalidad en el panorama de las letras femeninas del momento. El hecho de no dirigir prensa específicamente para mujeres, abriendo su escritura hacia temáticas generales, es un rasgo particular y de enorme singularidad dentro de la tipología hemerográfica patrocinada por mujeres en el siglo XIX en España. La renuncia a las típicas secciones y ocupaciones entendidas como femeninas, ofreciendo un tratamiento alternativo al dominante modelo del «ángel del hogar», molde conformador de una supuesta esencia femenina como ser doméstico, sumiso y entregado, las colocó fuera del discurso normalizador dominante, al margen de la literatura pedagógica y profundamente moralista destinada a las mujeres ${ }^{11}$. Con todo, reconstruir sus vidas se parece mucho a realizar una labor detectivesca que, partiendo de fragmentos parciales e inconexos, logre recomponer una cadena vital lo más completa posible. El trabajo no resulta fácil y muchas veces el seguimiento de pistas en determinadas fuentes de información no ofrece resultado alguno, tal es el caso de las fuentes testamentarias, mudas en este caso. En otras ocasiones, del exhaustivo y pesado rastreo en los padrones apenas aflora algún tipo de información de interés. No obstante, hasta el momento, podemos aportar trazos gruesos pero significativos de sus vidas, que ya adelantamos en otra ocasión ${ }^{12}$.

10. SimÓn PALMER, Carmen, Escritoras españolas del siglo XIX. Manual biobibliográfico, Madrid, 1991 (notas bibliográficas de $\mathrm{M}^{\mathrm{a}}$ Josefa Zapata en pp. 720-721, y mínima alusión a Margarita Pérez de Celis, tan sólo como directora de El Nuevo Pensil de Iberia en p. 552); CARMONA GONZÁlez, Ángeles, Escritoras andaluzas en la prensa de Andalucía del siglo XIX, Cádiz, 1999 (alusión a Margarita Pérez de Celis en pp. 210-211 y Ma Josefa Zapata en pp. 278-279); MARTíneZ, Cándida; PASTOR, Reyna; DE LA PASCUA, Ma José y TAVERA, Susanna, Mujeres en la Historia de España. Enciclopedia Biográfica, Barcelona, 2000 (recoge la biografía de Margarita Pérez de Celis en pp. 628-629).

11. BLANCO, Alda, Escritoras virtuosas: narradoras de la domesticidad en la España isabelina, Granada, 2001.

12. Espigado Tocino, Gloria, «Precursoras de la prensa femenina en España: $M^{a}$ Josefa Zapata y Margarita Pérez de Celis», en Vera BALANZA, M ${ }^{a}$ Teresa (ed.), Mujer, cultura y comunicación. Entre la historia y la sociedad contemporánea, Málaga, 1998, pp. 171-175. 
Comenzando con la que parece tener más edad, $\mathrm{M}^{\mathrm{a}}$ Josefa Zapata y Cárdenas, nacida en Cádiz en torno a la década de los veinte, de padre sevillano y madre arcobricense, pertenecería a la primera generación de escritoras románticas de las que nos habla Susan Kirkpatrick ${ }^{13}$. De orígenes hidalgos, pero de familia venida a menos, pronto conocería las estrecheces económicas de las mujeres que permanecen solteras y solas. Habiendo comenzado su aventura literaria a mediados de los cuarenta, con colaboraciones en la revista literaria gaditana El Meteoro (1845), los reveses de crítica que pudo recibir explican su desengaño y su largo silencio hasta la etapa en que asume la dirección de sus propios periódicos. La muerte fulminante de sus padres a raíz de la epidemia de cólera de 1854 resulta determinante para espolear de nuevo su vocación literaria y sus ansias de cambio social. Resulta más difícil, en cambio, establecer los orígenes familiares de su amiga Margarita Pérez de Celis y Torhbanh, nacida también en Cádiz y posiblemente algo más joven que la anterior. Si su primer apellido resulta habitual en las listas de comerciantes de la ciudad de Cádiz, su apellido materno nos revela una ascendencia extranjera cuyo origen está aún por determinar. Menos explícita que $\mathrm{M}^{\mathrm{a}}$ Josefa en sus escritos sobre los pormenores de su existencia, poco más podemos ofrecer sobre ella. Cuando recuperamos su nombre en los padrones de vecindad de Cádiz es para encontrárnosla junto a $\mathrm{M}^{\mathrm{a}}$ Josefa Zapata compartiendo con ella aficiones literarias, empresas periodísticas y vida en común. Esto ocurre en el año de 1862, cuando ya habían protagonizado y cerrado la serie de los «Pensiles», pero cuando aún quedaba por afrontar la edición del último periódico, La Buena Nueva. Los años que median entre estas dos experiencias tuvieron que ser muy duros para las dos mujeres. Se ganaban la vida como bordadoras o costureras, rememorando los oficios de algunas de las socialistas francesas más destacadas. El auxilio caritativo de personas allegadas también tuvo que dejar un poso amargo en las que se saben seres dependientes por antonomasia. Por si fuera poco, un grave contratiempo aquejó a $\mathrm{M}^{\mathrm{a}}$ Josefa que, por entonces, se estaba quedando ciega, asunto que trasciende a sus composiciones poéticas, utilizada como metáfora de la ceguera social ante la pobreza y la marginación de los desheredados de la tierra. Las dificultades llegaron a tal extremo que, desde la publicación madrileña La Violeta, se abrió una suscripción en 1863 para obtener fondos suficientes con los que afrontar la operación de cataratas que precisaba la escritora gaditana que, finalmente, pudo ser operada por un especialista en su propia ciudad ${ }^{14}$. Los años siguientes traen cambios de

13. Kirkpatrick, Susan, Antología poética de escritoras del siglo XIX, Madrid, 1992.

14. La ceguera fue una realidad física y literaria entre las escritoras victorianas y podríamos emparentar esta constante con la escritura en trance propia del espiritismo de la época 
domicilio de estas compañeras que permanecen solteras y unidas por el infortunio y por la edición de La Buena Nueva. No parece que haya mejorado su suerte cuando comparten domicilio con otras mujeres, viudas con hijas, que se dedican como ellas al duro oficio de la costura. El último registro vecinal data del año de la República, después ambas desaparecen de nuestra vista y tan sólo en 1878 volvemos a tener información de Margarita, que vive en una casa de vecinos en uno de los barrios más populares de Cádiz. Su trabajo de cordonera, más adelante de cigarrera, no desentona en un contexto de salineros, zapateros, jornaleros y marineros, hasta que, finalmente, una congestión cerebral diera fin a su vida, siendo enterrada, olvidada por todos, el 30 de noviembre de 1882.

Ocupándonos ahora de su labor editorial y haciendo una breve presentación de los periódicos por orden de aparición diremos que el primeros de ellos, El Pensil Gaditano. Periódico de Literatura, Ciencias y Artes, vio la luz a finales de 1856 y su periodicidad parecía ser quincenal. No tuvo excesiva continuidad, ya que hacia el mes de agosto pudo aparecer El Pensil de Iberia. Periódico de Literatura, Ciencias, Artes y Teatros. Todo parece indicar que pasó a tener una periodicidad decenal y continuó la numeración del anterior. La serie más larga conservada pertenece a la tercera época del periódico en la que adopta el título de El Nuevo Pensil de Iberia. Periódico de Literatura, Ciencias, Artes y Teatros, con periodicidad también decenal que se editó a partir del 10 de octubre de 1857. En este caso, sí se iniciaría nueva numeración que alcanza 44 números, hasta el 30 de diciembre de 1858. La cuarta y última época del periódico se inaugura con la aparición de El Pensil de Iberia. Revista Universal Contemporánea, tras tres meses de silencio, el 10 de abril de 1859. En esta ocasión se llegó a editar trece números con ciertas irregularidades en las entregas, debido a los serios problemas económicos por los que atravesó, terminando sus días, no obstante, por la acción de la censura que abortaría este primer intento editorial de $\mathrm{M}^{\mathrm{a}}$ Josefa y Margarita, que desistirían, por unos años, en su empeño ${ }^{15}$.

En todas estas publicaciones, ambas mujeres tienen un protagonismo definitivo, haciéndose cargo de la dirección y confección de buena parte de los artículos, traducciones y poesías publicadas. Resulta también fundamental la colaboración de José Bartorelo Quintana, otro pilar básico en la edición de

que también utilizan las escritoras, GILBERT, Sandra y GUBAR, Susan, La loca del desván. La escritora y la imaginación literaria del siglo XIX, Madrid, 1998, p. 468.

15. Los números de estos periódicos pueden ser localizados en varios fondos hemerográficos y archivísticos: el Casino Gaditano de Cádiz, el Archivo Histórico Provincial de Cádiz y la Hemeroteca Municipal de Madrid. 
estos periódicos. Se trata del médico demócrata, hermano de Enrique Bartorelo, otro destacado miembro del partido, que poseía un taller de fotografía, donde se reunían los simpatizantes republicanos de la ciudad, y con el que se le suele confundir en ocasiones. La relación de colaboradores expresa elocuentemente el alineamiento político e ideológico en este punto de intersección entre las ideas foruieristas y republicanas, pudiendo citar a Fernando Garrido, publicista incansable, autor de una monumental Historia de las Clases Trabajadoras, a Sixto Cámara, desaparecido en la insurrección de1859, al que fuera Presidente de la Primera República, Francisco Pi y Margall, al destacado federalista Roque Barcia, al dirigente obrerista Roberto Robert, al inventor del Ictinio y también difusor del socialismo saint-simoniano Narciso Monturiol, junto a otras personalidades menos conocidas, provenientes también del ámbito demócrata y filorrepublicano como el granadino Antonio Quiles, fundador de otro periódico fourierista como La Verdad en 1857, el malagueño Federico Ferredón y el profesor y pedagogo republicano Hermengaudio Cuenca Arias. También hubo colaboraciones femeninas, entre las que destacarían Rosa Butler, Francisca González Ruiz, Ana Ma Franco, Ángela Arizu, Pilar Payans, Adela de la Peña y Joaquina García Balmaseda. Por lo que respecta a la enigmática Rosa Marina, autora del folleto La Mujer y la Sociedad, prologado por Margarita Pérez de Celis, su identificación resulta algo problemática y hay posturas que la identifican tanto con $\mathrm{M}^{\mathrm{a}}$ Josefa Zapata como con la propia Margarita Pérez de Celis, sin que podamos desdeñar la posibilidad de que responda a una firma aún sin esclarecer ${ }^{16}$.

Pasarían seis años antes de que viera la luz La Buena Nueva. Periódico de Literatura, Ciencias, Artes e Industrias, última de las publicaciones emprendidas por las fourieristas gaditanas. Bajo la dirección de $\mathrm{M}^{\mathrm{a}}$ Josefa Zapata, se publicarán diez números entre el 15 de diciembre de 1865 al 15 de abril de 1866, con periodicidad semanal, en teoría, pero con enormes irregularidades en sus entregas. Sus colaboradores fijos, de nuevo, son $\mathrm{M}^{\mathrm{a} J o s e f a}$ Zapata, Margarita Pérez de Celis y José Bartorelo. Sigue firmando artículos Fernando Garrido y se suman José Mañé y Flaquer, C.P. Rioja, José Joaquín de Mora y Antonio M. de Flores. Las damas invitadas serán Ángela Arizu y María García de Escalona. También las incidencias de este periódico fueron múltiples y apuntan,

16. Antonio Elorza es partidario de la primera interpretación e Inmaculada Jiménez Morell de la segunda. Vid. JimÉNEZ MORELL, Inmaculada, La prensa femenina..., p. 106. 
igualmente, a graves contratiempos económicos y a problemas de censura que acabarían con sus días, como había ocurrido con sus antecesores ${ }^{17}$.

Amparadas en un afán literario, el contenido de poemas y artículos no se privarán, empero, de hacer una exhaustiva crítica a la realidad político-social terminando por concitar la atención de las autoridades civiles y eclesiásticas. La exaltación de la figura emblemática de Charles Fourier, el continuo llamamiento a las clases desheredadas para constituir la unión de los trabajadores en asociaciones estables, la participación de figuras literarias situadas en los márgenes del radicalismo político y, finalmente, el llamamiento a las mujeres a trastocar el orden doméstico, constituían extremos difícilmente digeribles para el moderantismo isabelino que gobernaba con contestación creciente de sus adversarios políticos excluidos. En una primera ocasión se dio al traste con la tirada de El Pensil de Iberia, en su cuarta época, al ser denunciados algunos artículos que se tenían como contrarios a la fe católica y a la moral cristiana. En concreto fue objeto de crítica, por parte del obispado gaditano, la serie que bajo el título «Leyendas morales» firmaba la enigmática Rosa Marina. En ella, la figura de Jesús, en nueva clave redentora, proponía un mensaje galvanizador para los sectores sociales menos favorecidos. Profeta de la sociedad del provenir, Mesías actualizado en el contexto de la miseria del siglo de la revolución industrial, la figura bíblica, con renovado vocabulario, proponía el trabajo mutuo, la asociación universal, la unión y la educación de los trabajadores, al mismo tiempo que anunciaba la condena y el fracaso de los ricos y poderosos, no ya en la vida ultraterrena, sino en un destino de justicia que debía cumplirse en la tierra, en un futuro no lejano. Por si fuera poco, y por el lado de la cuestión femenina, la reforma del matrimonio y la denuncia de la hipocresía social en torno al adulterio eran extremos intolerables desde el punto de vista de la jerarquía eclesiástica y de la autoridad política, representada por el Obispo y el Gobernador Civil, respectivamente. La explicación del modelo fourierista fue objetada igualmente por panteísta, desde el punto de vista religioso, y tachada de socialista, desde el punto de vista económico, entendida como un ataque al principio de la propiedad individual. Desde la publicación, aunque se intentó solventar estos problemas suspendiendo las entregas de los artículos contestados, no se pudo evitar la recogida y suspensión de números sueltos y, finalmente, bajo la advertencia de la obligación de firmar todas las contribuciones, se hizo muy duro responder a la imposición de una multa de 500 reales, pagaderas en un plazo de 30

17. Los expedientes de censura han sido consultados en la sección de «Imprenta y Prensa del Gobierno Civil, (1813-1867)» del Archivo Histórico Provincial de Cádiz, Leg. 120121-122 y 124. Los recoge también Antonio Elorza en su trabajo ya citado. 
días, determinación final de la actuación censora. La historia se vuelve a repetir con La Buena Nueva y el Gobernador Civil recibe igualmente notificación alarmante del contenido de esta publicación que, de nuevo, es identificada como propagandista del «Sistema Societario». Intolerable será también, a ojos del censor, la poesía que Margarita Pérez de Celis destina a una encendida pasión carnal que se consuma más allá de la muerte. De disparate es calificada su inspiración y nefasta su escritura que se relaciona con peligrosas corrientes espiritistas detectadas desde hace una década en la ciudad. La retirada de la licencia, sin menoscabo de la multa correspondiente, es la recomendación elevada a la autoridad para una publicación que hace ostentosamente profesión de fe fourierista, ensalzando la figura de Charles Fourier, al que estas autoridades estiman como el más peligroso pensador, «por encima de Owen o Saint-Simon», y que predica sin tapujos la subversión social.

\section{Los perfiles de la mujer profeta}

Llegados a este punto, es hora de que centremos nuestro interés en la escritura de estas dos mujeres, alma y sostén de las cuatro etapas de los Pensiles y de la Buena Nueva. $\mathrm{M}^{\mathrm{a}}$ Josefa es la más prolífica de las dos y suma un total de 39 escritos, en prosa o en verso, más un par de traducciones, de considerable extensión, que atraviesan diferentes etapas de vida del «Pensil». Por su parte, Margarita colabora con un total de 29 autorías en el total de los 70 números analizados. La primera característica a destacar es la preeminencia del verso sobre la prosa como forma de expresión elegida. La estética de la época, propia del movimiento romántico, muestra una predilección por el metro y la rima, en una práctica cultural muy extendida socialmente y que exploran, incluso, personalidades políticas de todo el espectro partidista, desde Cánovas del Castillo hasta Fernando Garrido o Sixto Cámara. En el caso de las mujeres, su uso no sólo se ve propiciado por las coordenadas estéticas dominantes del momento, sino que encuentra aliento en las aptitudes concedidas al sexo, tales como la sensibilidad y la imaginación, imprescindibles para el cultivo del género. No obstante, como nos ha advertido acertadamente Susan Kirkpatrick, la subjetivación de un «yo», autónomo, rebelde, trasgresor, dotado, por añadidura, de conciencia política, como es el caso de la identidad del genio romántico, concuerda con las atribuciones del sexo masculino, pero supone un problema en el caso de las mujeres autoras, determinadas por una naturaleza absolutamente distinta, según dictaminan los discursos morales 
y científicos de la época ${ }^{18}$. Lo único que cabe hacer es procurar un acomodo no conflictivo, circunscribiéndose a temáticas socialmente aceptadas para las mujeres, relacionadas con su rol de cuidado o, en una operación arriesgada, como el caso que nos ocupa, escribir al límite de esas mínimas posibilidades abiertas para las que quieren dejar de ser musa, objeto del canto, y convertirse en sujeto expresivo, bardo inspirado.

El sentimiento amoroso será principal motivo de inspiración y, sin duda, la palabra «amor» es el vocablo más repetido en las composiciones, tanto de $\mathrm{M}^{\mathrm{a}}$ Josefa como de Margarita. No hay probablemente poema en el que no haga acto de presencia y se convierta en el eje central, en el término nuclear de la expresión lírica. Descritas como seres para el amor, las mujeres no dejaron de tener serias cortapisas para expresarse, en cambio, de forma desinhibida sin llegar a causar escándalo. Las alternativas puestas en juego requerirán la desactivación de toda connotación sexual del lenguaje amoroso empleado, haciendo de familiares y amigos el objeto del canto poético. Los casos más típicos serán los poemas dedicados a padres, madres, tías, parientes en general y, también, a amigos y amigas. Estas últimas sirven para expresar intensos sentimientos de sororidad que caracterizan la «hermandad lírica», la red de apoyo que tejen entre sí estas escritoras, y que, a veces, se materializa en poemas de reconocimiento y amistad que incluyen alusiones moderadamente libidinosas, en un cruce entre sentimientos y reglas poéticas ${ }^{19}$. Impelidas a afrontar la atracción amorosa entre los sexos, ésta se hará desde la metamorfosis del cuerpo, encerrando en la metáfora de la flor silvestre y del pajarillo enjaulado, como elementos más frecuentes, el sentimiento de frustración de aquellas que carecen de libertad y de iniciativa. Todos estos artificios serán utilizados por nuestras autoras, no sin que encontremos a Margarita Pérez de Celis más osada en la expresión de un sentimentalismo menos cortapisado que, en ocasiones, prescinde de recursos defensivos, entablando un diálogo franco entre los amantes, que alarmará y movilizará, como ya dijimos, a las autoridades censoras ${ }^{20}$. Sin embargo, aparte de los usos aludidos, destaca la variante amorosa, neutra desde el punto de vista sexual, pero volcada igualmente hacia el ámbito de los afectos no privados sino públicos. Se trata, en

18. KiRKPATRICK, Susan, Las románticas. Escritoras y subjetividad en España (1835-1850), Madrid, 1991, p. 20.

19. MAYORAL, Marina, «Las amistades románticas: confusión de normas y sentimientos», en MAYORAL, Marina (ed.), Escritoras románticas españolas, Madrid, 1990, p. 44. y KIRKPATRICK, Susan, «La «hermandad lírica», de la década de 1840», en MAYORAL, Marina (ed.), Escritoras románticas..., pp. 25-42.

20. Este será también un rasgo de la joven Gertrudis Gómez de Avellaneda según KiRKPATRICK, Susan, Antología poética de escritoras..., p. 23. 
primera instancia, de un uso cristiano del término, una alusión al amor al prójimo, en definitiva, al cumplimiento de un mandato divino, que no es ajeno, por lo demás, a un empleo fourierista del concepto, en su acepción más espiritual, que proclama la libertad de las pasiones armonizada en la Ley de Atracción Universal, ley fourierista que dictamina que la libre inclinación hacia los seres y las cosas procurará el bien y el progreso de la humanidad. Se trata entonces del amor sublime, del amor concebido no ya, únicamente, como principio religioso sino como ley de la naturaleza, tenido como una misma cosa, y en cuya observancia cifra la especie humana su felicidad ${ }^{21}$.

La alusión a la divinidad es el otro extremo recurrente en sus poesías. La segunda palabra más utilizada es Dios, observado como el gran hacedor del universo, el inspirador de esta ley divina basada en la atracción y el amor universales. Sin que se altere el pensamiento fundamentalmente religioso de Charles Fourier, no estamos ante una desviación del mismo, quizá sí ante un abuso. Además, Cristo, Jesús, es visto como héroe salvador de los desheredados y propagador de un mensaje emancipador que vuelve los ojos hacia el primitivo cristianismo, como propagara con éxito Lamennais, el «gran profeta de la Democracia humanitaria» ${ }^{22}$. Completa el bagaje de estas escritoras la continua inspiración bíblica, a la par que sorprende la ausencia de toda mención a la jerarquía, a los intermediarios de la fe que profesan. Esta instrumentalización del mensaje evangélico como medio de subversión social constituye el alegato de protesta y de búsqueda de la justicia no ya en el más allá, sino en el más acá de la tierra, referida en ocasiones poéticamente como el globo o la esfera. En cualquier caso, para la mujer, hablar desde los principios doctrinales del cristianismo es un recurso hábil, inteligente, para arriesgar en la crítica poniéndose a resguardo de todo intento de desautorización ${ }^{23}$. La Iglesia está implicada fundamentalmente en la elaboración del discurso moral hacia las

21. También el owenismo hará una exaltación del sentimiento amoroso, comparándolo con un torrente, una fuerza de la naturaleza, lo que no impedirá a Owen lanzar su critica, hacia 1817, hacia el concepto de amor estrecho que poseía la religión institucionalizada, algo que lo acerca a la concepción amorosa de Godwin o Shelley, y a la del propio Fourier. TAYLOR, Bárbara, Eve and the New Jerusalem. Socialism and Feminism in the Nineteenth Century, London, 1983, p. 42.

22. Miguel GonZÁlez, Román, La pasión revolucionaria. Culturas políticas republicanas y movilización popular en la España del siglo XIX, Madrid, 2007, p. 75.

23. TAYLOR, Bárbara, «Por el amor de Dios. Religión e imaginación erótica en el feminismo de Mary Wollstonecraft», Studia Histórica. Historia Moderna, no 19 (1998), pp. 117138. Como nos explica esta historiadora, al fundamentar las raíces eminentemente religiosas del feminismo practicado por la escritora inglesa, la literatura puritana, con su énfasis en la democracia de la gracia de Dios, ayudó a construir un lenguaje aseverativo en boca de mujer. 
mujeres. El catolicismo ha valorado finalmente el carácter emancipador que el cristianismo ha tenido en el destino de la mujer superando etapas históricas dominadas por la barbarie. Bajo estas coordenadas y como consecuencia de ello, la dignificación de la mujer, y la consecuente feminización del rito, más que un efecto de la doctrina predicada por Cristo, tal como explica Inmaculada Blasco, es «un elemento más de las atribuciones de género derivadas del imaginario social moderno», armados contra el proceso de secularización creciente $^{24}$.

La posición de nuestras escritoras resulta, sin embargo, más temeraria, al entrelazar al mismo tiempo el mensaje de salvación religiosa y de emancipación social, no recomendando la resignación cristiana precisamente. Ellas son las anunciadoras de la Buena Nueva, del cambio fundamental que se ha de operar en el orbe simplemente por el cumplimiento que hagan los hombres de la ley divina que es, como hemos visto, ley de amor, pero también ley de justicia, libertad, igualdad y fraternidad, palabras también de profuso uso en una combinación entre cristianismo y liberalismo que resulta inquietante en la España de aquellos tiempos ${ }^{25}$. Todo ello pasado por el tamiz del socialismo utópico, fourierista por más señas, que trae a colación la mención de las series, el familismo, el grupismo, la unión, la atracción universal, la armonía, el societarismo, vocablos de insistente presencia en sus composiciones poéticas y que no hacen sino beber en las fuentes léxicas del maestro Fourier. Sin olvidar que el apego ilustrado a la razón, a la ciencia, frecuentemente aludida, supone un ingrediente añadido por parte de estas escritoras, en una combinación que confía y cree posible la adecuación del cristianismo con el demoliberalismo, el socialismo y el racionalismo-cientifismo.

Definitivamente, el papel fundamental de estas escritoras es el de anunciar el advenimiento de una nueva era para la humanidad. Es decir, su impostura, que así podríamos llamar al acto de apropiación de una identidad como la del profeta, tradicionalmente asumida por el varón, es la del ser que,

24. De este modo, el catolicismo, pese a las diferencias que pudiera presentar con el protestantismo y las precisiones que se pudieran hacer en torno al potencial emancipador para el sexo de uno y otro, también procuró un acercamiento preferente de las mujeres, observadas como reserva moral y propagandistas eminentes de la Fe. Vid. BLASCO HERRANZ, Inmaculada, «Género y religión: de la feminización de la religión a la movilización católica femenina: una visión crítica», Historia Social, no 53 (2005), pp. 119-136.

25. «Mas no espante a los señores, los colores/ Del Pensil al ver las flores:/ Que mi lema es, libertad e igualdad,/ Y en Jesús, fraternidad:/ Y más que obtener favores por errores,/ Quiero exponer con lealtad, la verdad». En Margarita Pérez de Celis, «La Verdad», El Nuevo Pensil de Iberia, 10-IX-1858. 
rarezas de la naturaleza, se ha encarnado en mujer ${ }^{26}$. El tono profético, la identificación con un «yo» dictaminador del porvenir, del futuro, futuro perfecto, las sitúa en un plano superior de autoridad, para asumir, eludiendo la tan traída y llevada debilidad del sexo, el trazo seguro del genio poético hecho mujer. Margarita escribe un poema que comienza en cada estrofa con un llamamiento a la humanidad, para que ésta responda al mensaje salvador y justiciero ${ }^{27}$. En otra ocasión, el anuncio de la fatalidad que aguarda a los tiranos procura la función profética en boca de $\mathrm{M}^{\mathrm{a}} \mathrm{Josefa}_{\text {Zapata }}{ }^{28}$. Esta misma sale al paso de la prohibición expresa que hace la Iglesia para que la voluntad divina no sea trasmitida a través de mujer. Frente a esto, reafirmará el derecho al apostolado, en una apuesta simbólica de la que no se nos escapa su peculiar trascendencia emancipadora.

«Porque débil muger, mi voz cortada, /Quedará oscurecida y despreciada./ ¿Quién eres me dirán, que preconizas/La nueva ley del amor, que olvida el sabio?/ ¿Por qué, pequeño ser, tu voz deslizas, / Y osas vibrar por tu rosado labio?/ Mas, de Jesús siguiendo la doctrina,/ Si alguno la examina/ Convencido será: predicad, dijo,/ Hombre o mujer, el Evangelio fijo ${ }^{29}$.

Porque es precisamente de la debilidad, de la mansedumbre y de la inocencia, de donde únicamente puede salir vigoroso el mensaje salvador, la mujer se sitúa en un lugar privilegiado para ser mediadora y trasmisora de la verdad libertadora.

«Mas no, yo lo diré, si acaso el eco/ De una débil mujer es escuchado;/ Si no reúne en el oído seco/ De aquel que no escuchar quiere obcecado,/ De una mujer que libertad proclama/ Para una humanidad que esclava gime, $/ Y$ con valor levanta el oriflama/ Y de fraternidad el lema imprime» ${ }^{30}$.

Dirimida la cuestión fundamental, la del derecho a tomar la palabra, a decir la verdad de forma favorable a sus pretensiones poéticas y políticas, tanto una como otra se sitúan en posición privilegiada para afrontar la cuestión más delicada y palpitante, la de, redenciones sociales aparte, ocuparse de la

26. Tal como estudiara Paul Benichou, en su aproximación a la literatura francesa de 1800 a 1850, habría que reconocer, a pesar de las diferencias doctrinales de cada uno de los escritores analizados (Chateaubriand, Lamennais, Saint-Simon, Comte, Edgar Quinet y Michelet), el nexo identificador de los que se erigen en profetas, anunciadores del progreso que encierra el porvenir. BeniCHOU, Paul, El tiempo de los profetas. Doctrinas de la época romántica, México, 2001 (1ª ed. 1973).

27. Margarita Pérez de Celis, «A la humanidad», El Nuevo Pensil de Iberia, 30-X-1857.

28. «Pronto se cumplirá la profecía/ Y detonando horrible cataclismo/ La Aurora brillará del nuevo día/ Y huirás al negro y pantanoso abismo». En $\mathrm{M}^{a}$ Josefa Zapata, «Luz y Justicia», El Nuevo Pensil de Iberia, 20-XII-1857.

29. $\mathrm{M}^{\mathrm{a}}$ Josefa Zapata, «La hija del pueblo», El Nuevo Pensil de Iberia, 10-I-1858.

30. $\mathrm{M}^{\mathrm{a}}$ Josefa Zapata, «El Abrazo fraternal», El Nuevo Pensil de Iberia, 30-XI-1858. 
emancipación de su propio sexo. Redención inexcusable e imbricada en la propia emancipación de la humanidad, en una tradición que más adelante encarnará en este país el feminismo de signo obrero y revolucionario, poco o nada apegado al gradualismo del feminismo liberal de las sufragistas. Por otra parte, las identidades femeninas, en el juego de espejos, de representaciones que proponen nuestras fourieristas, son variadas y cumplen con los contenidos del imaginario social utilizado siempre de forma favorable a los intereses emancipadores. De este modo, acudirá a la cita la mujer o las mujeres, en plural, recurso, este último, que demuestra tanto la diversidad, la pluralidad, como el resultado de un factor contable de particular trascendencia al referir a la mitad de la humanidad. Sin duda alguna, también se hará alusión a la madre, la esposa, la hija, es decir a las formas habituales de designación de la feminidad a través del parentesco con el varón más cercano. Claro está que también se evocarán las formas de estar que poseen mayor carga emotiva y por tanto mayor potencial perturbador de conciencias: la viuda, la huérfana, la trabajadora, la menestrala, la cautiva, la esclava, la mártir, etc., figuras situadas en los márgenes sociales, como requiere la estética de heroicidad romántica, por un lado, y el mensaje vindicativo y justiciero que anuncia el final de los tiranos, por otro, dos objetivos, uno estético y el otro político, resueltos a la vez.

En cualquier caso, la mujer se reviste de virtud, de unos atributos que si bien, podría argumentarse, no son los mismos que facultan al hombre para alcanzar sus derechos, son tan dignos como los de aquél y acaso puedan constituir una base diferencial para sostener la ciudadanía de las mujeres. Es más, la mujer es representada, como hiciera Mary Wollstonecraft desvelando una estrategia del feminismo primigenio, como el ser moralmente superior, digno de la misión más excelsa, cual es la de servir de guía en la emancipación humana. A su lado, el hombre es dibujado con trazos negativos, como tergiversador de la ley divina, como opresor de sus semejantes, poseedor de una ambición desmedida, devastador de la tierra, semillero del sentimiento de guerra, ruina del planeta. Particularmente, se le representa como el subyugador de la tríada predilecta de seres que existen para Fourier: los niños, los ancianos y las mujeres:

« $\mathrm{Y}$ adonde la mujer en su clausura,/ exenta de su dulce libertad,/ anhela amar, cual signo de ventura,/ y el mundo no comprende su lealtad./iVeis al hombre! Su tierna compañera/ esencia digna de su propio ser, /cortando el paso a su feliz carrera,/Cual juguete la juzga a su placer./Y a la que huyendo de sus torpes lazos,/Resiste con firmeza y con valor,/Su corazón destrozan a pedazos,/Víctimas de la befa y el rencor./Y si alguno defiende sus derechos/ 
Cual demente le anuncian en tropel,/Que la grandeza de los nobles pechos,/ El mundo la desdeña en su babel» ${ }^{31}$.

Es cierto que no puede hablarse de un programa de exigencias femeninas en asociación militante. No existe todavía una petición explícita de igualdad y de vindicación de ciudadanía que nos haga sospechar una mínima movilización de las mujeres. Y en ocasiones, domina la moderación y la contención de lo exigido. No parece se esté cuestionando el orden familiar y el papel reservado que las mujeres juegan en él, como tampoco será la primera vez ni la última que se utilizará la maternidad como plataforma vindicativa, usada estratégicamente para representar la utilidad social de las mujeres, como se desprende de este poema de $\mathrm{M}^{\mathrm{a}}$ Josefa Zapata en el que alude al papel educador de Cornelia, la matrona romana por excelencia.

«Oíd matronas, el sublime acento/ de la fama veraz, seguid la estrella/ que a Cornelia guió, mi voz ostento/ para imploraros que sigáis su huella/ vosotras, de virtudes ornamento/vosotras, atended a mi querella/ y donde el eco de mi lira vibre/ hará la educación al hombre libre» ${ }^{32}$.

Por unos momentos podemos llegar a pensar que antes que la igualdad se trata de exigir y obtener la libertad de las mujeres. Nuestras fourieristas manifiestan prioridades y quieren conseguir la manumisión de la esclava, y el vocablo no es baladí, ya que con él se señala la secuencia lógica que deben tener las cosas. En un contexto histórico donde se está dirimiendo la abolición de la esclavitud, con la expansión del movimiento antiesclavista a un lado y otro del Atlántico, la asimilación de la mujer a la imagen del esclavo (sobra señalar la estrecha relación histórica del feminismo con el movimiento abolicionista), procura un banco léxico de infinitas posibilidades para la causa de las mujeres. Como nos recuerda Geneviève Fraisse es la imagen elegida por John Stuart Mill para su obra vindicativa de los derechos femeninos, mientras que el rearme misógino de la época en boca de Augusto Comte se adhiere a la imagen de la menor, de la infante, con ánimos de desactivar o suavizar, al menos, los términos del discurso emancipista ${ }^{33}$.

«Y al que apiadado y por la ley sagrada/ sin del mundo temer la vil ofensa/ valiente se lanza a la defensa/ de la mujer que vive esclavizada./ Nosotras, proclamando los derechos/ que nos dió el alto espíritu y natura/ la frente alzando y con el alma pura/ aunque de los tiranos al despecho. / La celeste

31. $\mathrm{M}^{\mathrm{a}}$ Josefa Zapata, «Amor Filial», El Pensil de Iberia, 20-IX-1857.

32. $\mathrm{M}^{\mathrm{a}}$ Josefa Zapata, «Cornelia, dama romana. Fragmentos de un dogma sobre la educación», El Nuevo Pensil de Iberia, 30-XII-1857.

33. FraISSE, Geneviève, Los dos gobiernos: la familia y la ciudad, Madrid, 2003. 
bandera tremolando/ de la justicia a la brillante lumbre/ la libertad, amor y mansedumbre/ iremos en falange proclamando» ${ }^{34}$.

Y aunque no se vislumbra en sus escritos el anatema a la organización familiar, célula tremendamente exclusivista y antisocial para el fundador de la escuela (cosa que tampoco suscribirán los discípulos varones, que cribarán al Fourier más molesto), coincidirán con él en la necesidad de dejar en libertad a las mujeres para que decidan unir sus destinos con los hombres que son objeto de su atracción pasional. La libertad en la elección de pareja para el matrimonio no es un tema menor y tiempo hace que es fuente de inspiración tanto para los tratados morales como para la creación literaria. Lo que sí es nuevo, y revolucionario, es denunciar la inferioridad de las condiciones de partida para las mujeres ante esa tesitura (ausencia de una formación adecuada, restricciones laborales fundamentales, etc.), como el origen de sometimientos indeseados, que suenan a venta y prostitución legal de los cuerpos, en matrimonios regidos antes por las conveniencias sociales que por el imperio del amor y la atracción.

De igual modo, la libertad se concibe también y fundamentalmente con el acceso y el cultivo de la ciencia, con mayúsculas, lo que es claramente alternativo a los límites formativos interpuestos por las lecturas morales de los discursos normativos propios de la domesticidad circulante. Es cierto que, con frecuencia, se enuncia este acceso a la educación bajo la coartada del cumplimiento de la misión adjudicada al rol maternal de cuidado, en un reconocimiento expreso de la influencia benéfica que las mujeres pueden realizar en el seno del hogar como educadoras de sus hijos. Ahora bien, si caemos en la cuenta de que toda novedad legal, coetánea a estas composiciones, será la ley de educación de Claudio Moyano de 1857, en la que por primera vez se dictamina una educación elemental y obligatoria para niños y niñas entre los seis y los nueve años, reclamar una formación completa, aún a costa de moderar su alcance, no deja de constituir una estrategia posibilista que acomoda el deseo unos pasos más allá de donde quiso llegar el legislador.

Junto a la libertad para educarse, la libertad para desempeñar un oficio. El acceso al trabajo, justamente retribuido, se muestra como una conveniencia para toda la comunidad familiar, ya que el trabajo de las mujeres exime al varón de la obligada manutención de la esposa, en una lectura muy fourierista de lo que debe ser la contribución del trabajo femenino al conjunto social, y de espaldas a lo que más adelante se ha de defender como «el salario familiar», que exige que el varón gane lo suficiente para sostener a la familia.

34. $\mathrm{M}^{a}$ Josefa Zapata, «Fourier», El Nuevo Pensil de Iberia, 10-V-1858. 
La actividad laboral resulta ser un instrumento de libertad que impide que la vía matrimonial sea forzada y es, a su vez, un reaseguro para las mujeres solas, solteras o viudas, que tengan además obligaciones familiares a su cargo. El temor al desclasamiento, debido a los desequilibrios que pueda introducir las transformaciones económicas que se están produciendo, es común al observado en la Francia revolucionaria del 48, donde destacadas activistas reclamaron una especial atención de los Talleres Nacionales hacia la mujer trabajadora. Junto a la defensa de la justa retribución para las mujeres de la clase obrera, también se insistirá en la apertura de oficios adecuados para las hijas de familia, las mujeres de la clase media, allí donde educación ofrezca un soporte a una capacitación mayor:

«Cuando libre elección su amor obtenga,/ La sana educación será la guía,/ Que sus derechos y deber sostenga,/ Las aulas se abrirán, allí donosas/ Dando estímulo y fruto a sus talentos,/ Y luciendo sus gracias pudorosas,/ Ganarán ellas propias sus sustentos» ${ }^{35}$.

Haciendo balance en este breve repaso por los mimbres y materiales simbólicos con que estas escritoras pretenden fundar una nueva imagen para la mujer, describiendo una línea sutil para la subversión, apreciamos la fidelidad a las diversas concepciones políticas que nutren los movimientos de izquierda europeos en la etapa romántica, haciendo confluir un humanitarismo cristiano con las concepciones demorrepublicanas, sin olvidar la preferencia y adscripción explícitas al socialismo utópico fourierista. Lo peculiar, en este caso, es la utilización instrumental de este discurso político al servicio de la mejora de la condición de la mujer. En los márgenes de la norma y de la moral subyugadora, estas escritoras proyectarán las capacidades reconocidas al sexo para, en una vuelta de tuerca, convertirlas en armas de redención. La proverbial cercanía de las mujeres a la espiritualidad religiosa, al ejercicio de una maternidad social atenta a los sufrimientos de la humanidad, las capacitan para el dictamen profético. La subida a la tribuna, la salida al ámbito público, siempre problemático para las mujeres, se escuda en este caso, como en otros precedentes europeos, en el recurso apostólico de las que simplemente quieren evangelizar. La estrategia adoptada resulta, sin embargo, fallida para burlar los sistemas de control. La autoridad civil y religiosa advertirá con acierto el peligro potencial que ésta encierra y neutralizará, mediante la censura, toda pretensión expresiva. Cortapisadas por severos obstáculos en su condición de mujeres solas, adscritas a doctrinas proscritas, serán doblemente rechazadas. Ni la una ni la otra gozarán del éxito literario ni del reconocimiento por su

35. $\mathrm{M}^{a}$ Josefa Zapata, «El abrazo fraternal», El Nuevo Pensil de Iberia, 30-XI-1858. 
labor como propagandistas de una idea salvadora. Silenciada su memoria, sería finalmente el feminismo del siglo XX el que las rescatará como semilla del cambio futuro, reconociendo en ellas la genealogía de arranque del feminismo de este país ${ }^{36}$. Ellas habrían sido capaces de realizar un llamamiento al sexo, al colectivo, demostrando la superación de la tópica representación de la mujer excepcional, única entre parias, para iniciar una lucha en común que emancipe, libere e iguale a todo el sexo.

36. Así lo consideraba Celsia Regis en La Voz de la Mujer, Madrid, 31 X-1928. Citado por FAGOAGA, Concha, La Voz y el Voto de las mujeres. El sufragismo en España, 1877-1931, Barcelona, 1985, p. 50. 